\title{
Einfaches Fließschema für die automatische Serumalbumin-Bestimmung mit dem Autoanalyzer SMA 6/60
}

\author{
Von A. v. Froreich und O. Müller-Plathe \\ Aus dem Zentrallaboratorium (Chefarzt: Dr. O. Mülle $\dot{r}$-Plathè) des Allgemeinen Krankenbauses Altona, \\ Hamburg
}

(Eingegangen am 12. Januar 1973)

\begin{abstract}
Für die photometrische Albuminbestimmung im Autoanalyzer SMA 6/60 mit der Bromkresolgrün-Methode ist eine Serumvorverdünnung erforderlich. Es wird ein Fließschema beschrieben, das die Serumverdünnung für den Na/K-Kanal nach Durchfließen des Dialysators als Vorverdünnung für die Albuminbestimmung benutż. Dadurch, daß ein bestimmter Anteil dieser Verdünnuung luftsegmentiert durch die Proportionierpumpe in den Albuminkanal gesaugt wird, läßt sich die Verschleppung stark vermindern. Die Messung erfolgt bei $610 \mathrm{~nm}$ in der 2,0 cm-Durchflußküvette. - Das Verfahren bewährt sich seit mehr als 6 Monaten in der Routine.
\end{abstract}

\section{A simple flow scheme for the automatic determination of serum albumin with the autoanalyzer SMA 6/60}

In the photometric determination of serum albumin by the bromocresol green method in the autoanalyzer SMA 6/60, predilution of the serum is necessary. A flow scheme is described, in which the dilution of the serum for the $\mathrm{Na} / \mathrm{K}$ channel, after passage through the dialyzer, serves as the predilution for the albumin determination. An aliquot of this diluted sample is separated by air and drawn into the albumin channel by the proportionating pump, thus greatly teducing carry over. Measurements ate made at $610 \mathrm{~nm}$ in the $2.0 \mathrm{~cm}$ flow through cuvette. The method has been used routinely for more than 6 months and proved satisfactory.

Die Serumalbumin-Konzentration ist ein wertvoller Parameter für die Intensivüberwachung, für die Kontrolle der Infusionstherapie und für die nephrologische Diagnostik. Thre Bestimmung über das Gesamteiweiß und die Protein-Elektrophorese ist für größere Analysenreihen zu umständlich. Deshalb wurde die $\mathrm{CO}_{2-}$ Bestimmung im SMA 6/60 aufgegeben und durch die nachfolgend beschriebene Albuminbestimmung ersetzt, so daß sich ein „Nieren-Elektrolyt-Profil", bestehend aus Natrium, Kalium, Chlorid, Albumin, Harnstoff-N und Kreatinin, ergab.

Die weit verbreitete Autoanalyzer-Albuminmethode mit Carboxy-2-hydroxy-4'azobenzol, genannt HABA, hat den Nachteil einer geringen Spezifität. Sie wird vor allem durch hohe Bilirubinkonzentrationen und in hämolytischen Seren gestört (1). Nach neueren Arbeiten $(1,2,3)$ zeichnet sich Bromkresolgrün als Farbstoff für die Albuminbestimmung durch eine besonders hohe Spezifität aus. Bilirubin stört in Konzentrationen bis zu $400 \mathrm{mg} / \mathrm{l}$ nicht, der Einfluß von Arzneimitteln scheint gering zu sein. (3). Optimale Reaktionsbedingungen für die manuelle Bestimmung des Albumins mit Bromkresolgrün wurden kürzlich in dieser Zeitschrift beschrieben (3). Adaptationen der Methode für den Autoanalyzer liegen vor $(2,4,5,6)$. Im folgenden wird ein speziell für den SMA 6/60 geeignetes, einfaches Verfahren angegeben.

\section{Material und Methoden}

Geräte

Autoanalyzer SMA 6/60 (Technicon) mit Filter $610 \mathrm{~nm}$ und $2,0 \mathrm{~cm}$-Durchflußküvette. h-förmiges Glasstück $\mathrm{HD} \mathrm{O}$ (Abb. 2), Technicon Nr. 116-0203-00.

Reagenzien

1. Bromkresolgrün (Merck, Nr. 8121)

2. Citronensäure z. A. (Merck, Nr. 244)

3. Brij 35, 0,3 kg/l (Technicon, Nr. T 21-0110-17)

4. Natronlauge, 0,1 mol/1 (Titrisol Merck, Nr. 9959/0001).

Herstellung des Farbreagenz (6)

1. Bromkresolgrün-Stammlösung $(0,6 \mathrm{mmol} / 1$ Bromkresolgrün) $838 \mathrm{mg}$ Bromkresolgrün in $20 \mathrm{ml} \mathrm{NaOH}(0,1 \mathrm{~mol} / \mathrm{l})$ lösen. Mit dest. Wasser ad 21 auffüllen. - Bei Raumtemperatur in dunkler Flasche mehrere Monate haltbar.

2. Citratpuffer $(0,5 \mathrm{~mol} / 1 ; \mathrm{pH} 4,0)$

$210 \mathrm{~g}$ Citronensäure $\cdot \mathrm{H}_{2} \mathrm{O}$ in 11 dest. Wasser lösen. Mit Natronlauge $(2,5 \mathrm{~mol} / \mathrm{l})$ auf $\mathrm{pH} 4,0$ einstellen und mit dest. Wasser ad 21 auffüllen. - Bei $+4^{\circ} \mathrm{C}$ vier bis sechs Wochen haltbar.

Trübe Lösungen verwerfen.

3. Gebrauchslösung (0,06 mmol Bromkresolgrün und $0,05 \mathrm{~mol}$ Citrat/l)

$\begin{array}{lr}\text { Bromkresolgrün-Stammlösung } & 400 \mathrm{ml} \\ \text { Brij-Lösung } & 16 \mathrm{ml} \\ \text { Citratpuffer } & 400 \mathrm{ml} \\ \text { dest. Wasser } & \text { ad } 41\end{array}$




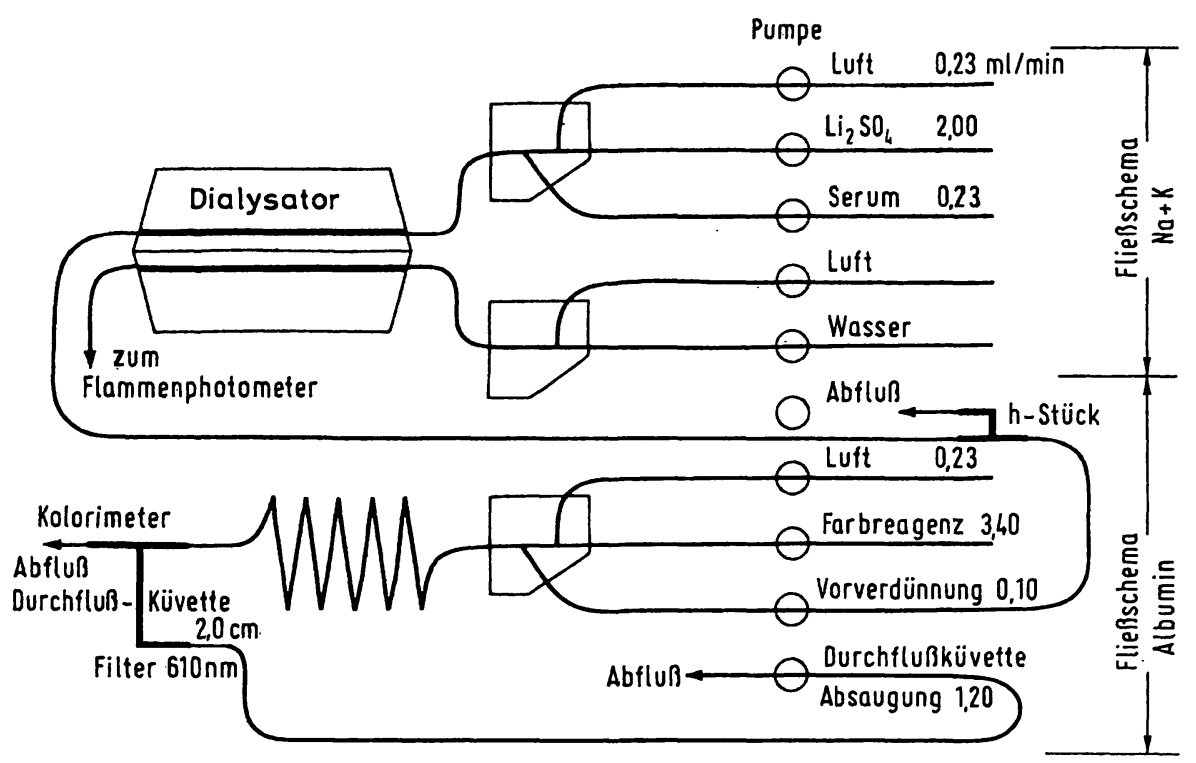

Abb. 1

Fließschema für die Albuminbestimmung mit dem Autoanalyzer SMA 6/60. Im oberen Teil der Abbildung ist das Fließschema für die $\mathrm{Na} / \mathrm{K}$-Bestimmung dargestellt. Aus der Serum/Li $\mathrm{SO}_{4}$-Verdünnung wird nach Passage des Dialysators ein kleiner Anteil luftsegmentiert als Vorverdünnung für die Albuminbestimmung benutzt. Die Vorverdünnung wird mit dem Farbreagenz gemischt, die Mischung luftsegmentiert und über Misch- und Verzögerungsschlangen dem Kolorimeter zugeführt

\section{Eichung}

Die Eichung erfolgte mit handelsüblichen Autoanalyzer-Einstellseren der Firmen Technicon und Hyland. Es empfiehlt sich, den angegebenen Albumingehalt mittels eines geeigneten Humanalbuminstandards $(2,3)$ zu überprüfen.

\section{Fließschema}

$\mathrm{Da}$ sich eine befriedigende Linearität der Methode nur bei einem hohen Verdünnungsgrad des Serums erreichen läßt, wurde zur Vereinfachung des Fließschemas die Serum/Lithiumsulfat:Verdünnung des Natrium-Kalium-Kanals nach Passage des Dialysators als Vorverdünnungsstufe für die Albuminbestimmung benutzt. Hierdurch und durch die anschließende Farbreaktion wird eine Endverdünnung des Serums von 1:340 erreicht.

Das Fließschema geht aus der Abbildung 1 hervor.

Es ist wichtig, daß das mit Lithiumsulfat verdünnte Serum unter Beibehaltung der Segmentierung entnommen wird. Das wird durch ein h-förmiges Glasteil erreicht (Abb. 2), in das der Entnahmeschlauch für den Albuminkanal so weit vorgeschoben wird, $\mathrm{da} ß$ Luftsegmente von $3 \mathrm{~mm}$ Länge zusammen mit der Vorver-

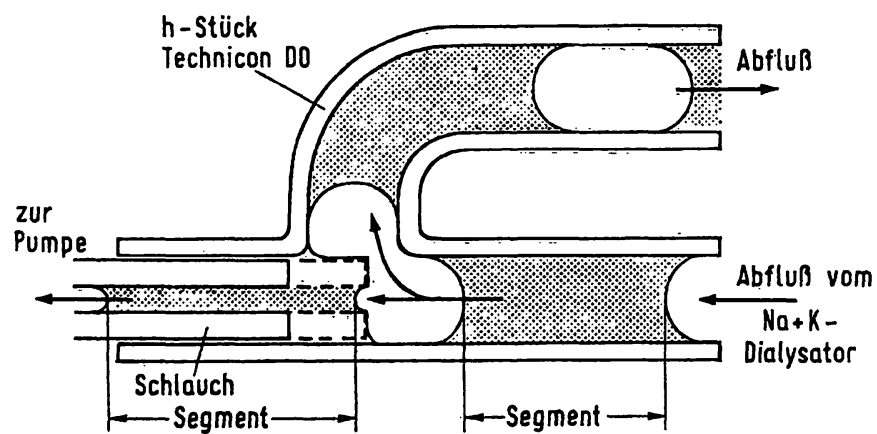

Abb. 2

Entnahme von Serum/Li, SO, als Vorverdünnung aus dem $\mathrm{Na} / \mathrm{K}$ Kanal. Der Entnahmeschlauch muB soweit (gestrichelt gezeichneter Teil) vorgeschoben werden, daß neben der Flüssigkeit auch ein Luftanteil entnommen wird. Die Luftsegmente sollen etwa $3 \mathrm{~mm}$ lang sein
Folgende Schläuche wurden verwendet:

1. Zur Vorverdünnung die üblichen Schläuche des Natrium/KaliumKanals:
a) Serum
b) Lithiumsulfat
$0,23 \mathrm{ml} / \mathrm{min}$ $0,23 \mathrm{ml} / \mathrm{min}$
0,025 inch $\varnothing$
0,073 inch $\varnothing$
0,025 inch $\varnothing$
orange-weiß
ion
2. Für die Farbreak
Serum
$0,1 \mathrm{ml} / \mathrm{min}$
$0,23 \mathrm{ml} / \mathrm{min} \quad 0,025 \mathrm{inch} \varnothing$
0,015 inch $\varnothing$
b) Guft

dünnung entnommen werden. Hierdurch wird eine wesentlich geringere Verschleppung erreicht, als bei Absaugung der Serumverdünnung ohne Luftanteil (Abb. 3).

\section{Zuverlässigkeitskriterien}

Der lineare Anzeigebereich, geprüft mit Verdünnungen von Humanalbumin, reicht von 0 bis $50 \mathrm{~g} / \mathrm{l}$ Albumin. Das entspricht dem diagnostisch interessierenden Konzentrationsbereich. Oberhalb von $50 \mathrm{~g} / 1$ kommt es zu einer allmählichen Abflachung der Kurve.

Die Ricbtigkeit hängt wesentlich von der Wahl eines korrekten Eichstandards ab. Solange keine Autoanalyzer-Eichstandards zur Verfügung stehen, deren Albuminkonzentration mit der Bromkresolgrün-Methode ermittelt wurde, muß der angegebene Albumingehalt mit einer Humanalbuminlösung überprüft werden. Es ergab sich eine gute Übereinstimmung der gemessenen Albuminwerte mit den aus der Gesamteiweißbestim-

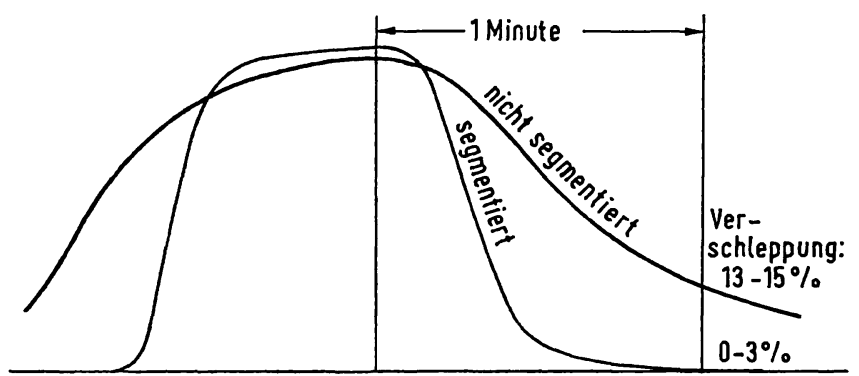

Abb. 3

Einfluß der Luftsegmentierung bei der Entnahme der Vorverdünnung auf die Verschleppung (Zeichnung nach Originalkurven vom SMA $6 / 60)$. Wird die Vorverdünnung gemäß Abbildung 2 luftsegmentiert durch die Proportionierpumpe gesaugt, so erhält man bei erheblich reduzierter Verschleppung ein für die Messung gut geeignetes Plateau 
mung (Biuretmethode) und der Cellulose-Acetat-FolienElektrophorese errechneten Werten, wie schon von anderen Autoren berichtet $(2,3,6)$.

Präzision

In der Serie: $\quad \mathrm{n}=25$

$$
\overline{\mathrm{x}}=39,96 \mathrm{~g} / \mathrm{l}
$$

$$
\begin{aligned}
\mathrm{s} & =0,2 \mathrm{~g} / 1 \\
\mathrm{VK} & =0,5 \%
\end{aligned}
$$

Von Tag zu Tag: $\quad \mathrm{n}=131$ (Juli bis Dezember 1972)

$$
\overline{\mathrm{x}}=36,6 \mathrm{~g} / \mathrm{l}
$$$$
\mathrm{s}=1,1 \mathrm{~g} / \mathrm{l}
$$

$\mathrm{VK}=3,0 \%$

\section{Literatur}

1. Miyada, D. S., Baysinger, V., Notrica, S. \& Nakamura, 338-344. - 4. Rodkey, F. L. (1965), Clin. Chem. 11, 478-487.

R. M. (1972), Clin. Chem. 18, 52-56. - 2. Doumas, B. T., Watson, W. A. \& Brggs, H. G. (1971), Clin. Chim. Acta 31, 87-96. - 3. Schirardin, H. \& Ney, J. (1972), diese Z. 10,

5. Hernandez, O., Murray, L. \& Doumas, B. (1967), Clin. Chem. 13, 701. - 6. Dow, D. \& Pinto, C. (1969), Clin. Chem. 15, 1006-1008.
Dr. O. Müller-Plathe Allg. Krankenhaus Altona 2000 Hamburg 50

Paul-Ehrlich-Str. 1 